\title{
Gambaran demensia vaskular pada pasien stroke nonhemoragik dengan diabetes melitus tipe 2 di poli saraf RSUD Sultan Syarif Mohamad Alkadrie Pontianak
}

\author{
Rachel Dhea Aprila ${ }^{1, *}$, An $\mathrm{An}^{2}$, Widi Raharjo ${ }^{3}$ \\ ${ }^{I}$ Program Studi Kedokteran, Fakultas Kedokteran, Universitas Tanjungpura, Kalimantan Barat, Indonesia \\ ${ }^{2}$ Departemen Neurologi, Fakultas Kedokteran, Universitas Tanjungpura, Kalimantan Barat, Indonesia \\ ${ }^{3}$ Departemen Ilmu Kesehatan Masyarakat, Fakultas Kedokteran, Universitas Tanjungpura, Kalimantan Barat, Indonesia \\ *Korespondensi: rchldhea@gmail.com
}

\begin{abstract}
Abstrak
Latar belakang: Demensia vaskuler (VaD/vascular dementia) menempati peringkat kedua penyebab utama demensia atau dikenal dengan istilah pikun. Demensia berkembang sekitar 15-30\% dalam kurun waktu 3 bulan setelah serangan stroke. Diabetes melitus tipe 2 merupakan faktor risiko independen stroke nonhemoragik yang dapat dimodifikasi. Sekitar 90\% kasus lebih sering terjadi pada individu dengan diabetes melitus tipe 2. Indonesia menempati urutan ke-6 dengan angka penderita diabetes sebanyak 10,3 juta jiwa di tahun 2017. Penelitian ini bertujuan untuk mengetahui gambaran demensia vaskular pada pasien stroke nonhemoragik dengan diabetes melitus tipe 2 di Poli Saraf RSUD Sultan Syarif Mohamad Alkadrie Pontianak. Metode: Penelitian deskriptif dengan pendekatan cross sectional. Pengambilan sampel dilakukan dengan teknik purposive sampling. Data diperoleh dari wawancara dan kuesioner penelitian MoCA-INA, HIS, ADL dan IADL. Hasil: Pasien stroke nonhemoragik lebih banyak laki-laki (57,9\%), kelompok umur 55-64 tahun (47,4\%), ibu rumah tangga (IRT) (34,2\%), tingkat pendidikan SMA (50\%). Dijumpai gangguan kognitif ringan sebesar 47,4\%, ADL tingkat ketergantungan ringan sebesar 57,9\%, IADL tingkat mandiri sebesar 42,1\% dan 94,7\% terdiagnosis VaD. Kesimpulan: Demensia vaskular banyak dijumpai pada pasien stroke nonhemoragik dengan diabetes melitus 2 .
\end{abstract}

Kata kunci: demensia vaskular, diabetes melitus tipe 2, stroke nonhemoragik

\section{Description of vascular dementia in non-hemorrhagic stroke patients with type 2 diabetes mellitus in neurology clinic at Sultan Syarif Mohamad Alkadrie Regional Public Hospital in Pontianak}

\begin{abstract}
Background: Vascular dementia $(\mathrm{VaD})$ is the second leading cause of dementia. Dementia developed in about $15-30 \%$ within three months after stroke. Type 2 diabetes is a modifiable independent risk factor for non-hemorrhagic stroke. Approximately $90 \%$ of cases are more common in individuals with type 2 diabetes. In 2017, Indonesia occupied the 6th ranks with 10.3 million people with diabetes. This study aims to determine the description of vascular dementia in non-hemorrhagic stroke patients with type 2 diabetes in Neurology Clinic at Sultan Syarif Mohamad Alkadrie Regional Public Hospital in Pontianak. Methods: The study was a descriptive study with cross-sectional design. Sample was chosen by purposive sampling. Data was obtained from interviews and MoCA-INA, HIS, ADL. and IADL questionnaires. Results: Non-hemorrhagic stroke patients in this study were mostly males (57.9\%), aged 55-64 years old (47.4\%), housewives (34.2\%), and high school graduates (50\%). Mild cognitive impairment was diagnosed in $47.4 \%$ cases, mild dependence in ADL in $57.9 \%$, independence level in IADL in $42.1 \%$ and diagnosis of $\mathrm{VaD}$ in $94.7 \%$. Conclusions: Vascular dementia is more often found in non-hemorrhagic stroke patients with diabetes mellitus 2.
\end{abstract}

Keywords: nonhemorrhagic stroke, type 2 diabetes mellitus, vascular dementia 


\section{Pendahuluan}

Orang Indonesia mengenal demensia dengan istilah pikun. Demensia menurut World Health Organization (WHO), merupakan suatu sindrom yang mana terjadi penurunan kognitif yang bersifat kronik. Meskipun menyerang individu tua, demensia bukanlah bagian normal dari proses penuaan. Sindrom ini ditunjukkan dengan terganggunya fungsi dalam mengambil keputusan, pemahaman, memori, berpikir, perhitungan, belajar, dan bahasa. ${ }^{1}$

Demensia yang timbul setelah serangan stroke diklasifikasikan sebagai demensia vaskuler. ${ }^{2} \mathrm{VaD}$ menduduki urutan kedua penyebab utama demensia setelah penyakit Alzheimer (Alzheimer's Dementia/AD). Demensia berkembang sekitar 15-30\% dalam waktu 3 bulan setelah stroke. ${ }^{3}$

Stroke disebabkan oleh kematian mendadak beberapa sel otak akibat kekurangan pasokan oksigen yang mengalir ke otak. ${ }^{4}$ Aterosklerosis intrakranial merupakan penyebab umum terjadi stroke nonhemoragik dan defisit kognitif. Perkembangannya sangat cepat bila ditemukan pada faktor risiko tertentu seperti hipertensi dan diabetes melitus. $^{5}$

Individu dengan diabetes melitus tipe 2 lebih cenderung mengalami obesitas, aterosklerosis arteri besar dan stroke. Diabetes menyebabkan berbagai perubahan mikrovaskular dan makrovaskular yang menimbulkan komplikasi klinis. Sekitar 90\% kasus lebih sering terjadi pada individu dengan diabetes melitus tipe 2. Diabetes melitus tipe 2 merupakan faktor risiko independen dari stroke nonhemoragik yang dapat dimodifikasi. ${ }^{6}$

Indonesia di tahun 2017, menempati urutan ke enam tertinggi di dunia dengan 10,3 juta penderita diabetes. $^{7}$ Data tahun 2017 menunjukkan jumlah kunjungan pasien diabetes melitus tipe 2 di RSUD Sultan Syarif Mohamad Alkadrie Pontianak mencapai 5.318 kunjungan.

Sejauh ini penelitian terhadap gambaran diabetes melitus tipe 2 dengan kejadian $\mathrm{VaD}$ masih kurang, khususnya di Indonesia. Bahkan sampai saat ini belum ada data resmi penderita $\mathrm{VaD}$ di Indonesia. Berdasarkan latar belakang masalah diatas, penulis tertarik untuk melakukan penelitian mengenai gambaran demensia vaskular pada pasien stroke nonhemoragik dengan diabetes melitus tipe 2 di Poli Saraf RSUD Sultan Syarif Mohamad Alkadrie Pontianak.

\section{Metode}

Penelitian ini merupakan penelitian deskriptif dengan pendekatan cross sectional untuk mengetahui gambaran demensia vaskular pada pasien stroke nonhemoragik dengan diabetes melitus tipe 2 di Poli Saraf RSUD Sultan Syarif Mohamad Alkadrie Pontianak. Pengambilan sampel dilakukan secara non-probability sampling dengan teknik purposive sampling.

Data primer didapat dengan mengisi kuesioner melalui wawancara langsung pada 38 pasien stroke nonhemoragik dengan diabetes melitus tipe 2 yang datang ke Poli Saraf RSUD Sultan Syarif Mohamad Alkadrie Pontianak tanggal 12 Agustus 2019 sampai 2 September 2019. Data sekunder diperoleh melalui rekam medik pasien yang sebelumnya telah disetujui oleh Kepala Instalasi Rekam Medik RSUD Sultan Syarif Mohamad Alkadrie Pontianak.

Sampel dalam penelitian ini adalah pasien yang memenuhi kriteria inklusi dan eksklusi. Kriteria inklusi penelitian ini adalah penderita stroke nonhemoragik dengan diabetes melitus tipe 2, bersedia menjadi subjek penelitian dan mampu menggunakan alat tulis. Kriteria eksklusi yaitu pasien mengalami stroke berulang, penderita buta huruf dan afasia.

Variabel bebas dalam penelitian ini adalah diabetes melitus tipe 2, sedangkan variabel terikat pada penelitian ini adalah demensia vaskular. Penelitian ini menggunakan instrumen berupa kuesioner dan rekam medik untuk memperoleh data. Kuesioner yang digunakan yaitu Hachinski Ischemic Score (HIS), Montreal Cognitive Assessment-Indonesia (MoCA-INA), Instrumental Activities of Daily Living (IADL) dan Activities of Daily Living (ADL). Status penderita diabetes melitus tipe 2 dan stroke nonhemoragik ditentukan berdasarkan diagnosis dokter dari rekam medik pasien.

HIS berguna dalam membedakan $\mathrm{AD}$ dan VaD. Skor untuk $\mathrm{AD} \leq 4$ dan $\mathrm{VaD} \geq 7$, demensia campuran memiliki skor 5-6. MoCa-INA menggambarkan tingkat kognitif pasien. Skor normal yaitu 26-30 sementara gangguan kognitif $0-25$. Gangguan kognitif dibagi menjadi gangguan kognitif ringan yaitu 20-25, gangguan kognitif sedang 10-19 dan gangguan kognitif berat 0-9. 
IADL dan ADL digunakan dalam menilai gangguan fungsional dalam aktivitas sehari-hari. Skor mandiri IADL yaitu 8, apabila ketergantungan ringan 5-7, ketergantungan berat 2-4 dan ketergantungan total $0-1$. Skor mandiri ADL yaitu 20, apabila ketergantungan ringan 12-19, ketergantungan sedang 9-11, ketergantungan berat 5-8, dan ketergantungan total 0-4.

\section{Hasil}

Penelitian telah dilakukan terhadap 38 pasien stroke nonhemoragik dengan diabetes melitus tipe 2 . Tabel 1 menunjukkan jumlah responden berdasarkan jenis kelamin yaitu, laki-laki sebanyak 21 orang $(55,3 \%)$ dan perempuan sebanyak 17 orang $(44,7 \%)$. Distribusi responden berdasarkan umur lebih banyak pada umur 55-64 tahun yaitu sebanyak 18 orang (47,4\%). Digambarkan distribusi responden berdasarkan pekerjaan lebih banyak pada Ibu Rumah Tangga (IRT) yaitu 13 orang $(34,2 \%)$ sedangkan berdasarkan tingkat pendidikan lebih banyak pada tingkat pendidikan SMA yaitu 19 orang (50\%).

Tabel 1. Distribusi pasien stroke nonhemoragik dengan diabetes melitus tipe 2

\begin{tabular}{lcc}
\hline \multicolumn{1}{c}{ Karakteristik } & $\mathrm{N}(38)$ & $\%$ \\
\hline Jenis kelamin & 21 & 55,3 \\
Laki-laki & 17 & 44,7 \\
Perempuan & & \\
\hline Umur & 1 & 2,6 \\
35-44 tahun & 9 & 23,7 \\
45-54 tahun & 18 & 47,4 \\
55-64 tahun & 9 & 23,7 \\
65-74 tahun & 1 & 2,6 \\
$\geq 75$ tahun & & \\
\hline Pekerjaan & 9 & 23,7 \\
Pensiunan & 13 & 34,2 \\
IRT & 11 & 28,9 \\
Swasta & 4 & 13,2 \\
PNS & & \\
\hline Tingkat pendidikan & 3 & 7,9 \\
SD & 6 & 19,8 \\
SMP & 10 & 50,0 \\
SMA & & \\
PT/Akademi & & \\
\hline
\end{tabular}

Distribusi responden berdasarkan tingkat kognitif yang diukur menggunakan kuesioner MoCA-INA lebih banyak pada gangguan kognitif ringan yaitu 18 orang $(47,4 \%)$ dapat dilihat pada Tabel 2. $\underline{\text { Tabel 2. Distribusi responden berdasarkan tingkat kognitif }}$

\begin{tabular}{lcc}
\hline \multicolumn{1}{c}{ Tingkat Kognitif } & $\mathrm{N}$ & $\%$ \\
\hline Normal & 6 & 15,8 \\
Gangguan kognitif ringan & 18 & 47,4 \\
Gangguan kognitif sedang & 11 & 28,9 \\
Gangguan kognitif berat & 3 & 7,9 \\
\hline
\end{tabular}

Distribusi responden berdasarkan tingkat ketergantungan pada aktivitas sehari-hari dengan menggunakan skor ADL lebih banyak pada ketergantungan ringan sebanyak 22 orang $(57,9 \%)$ dapat dilihat pada Tabel 3 .

Tabel 3. Distribusi responden berdasarkan skor ADL

\begin{tabular}{lcc}
\hline \multicolumn{1}{c}{ ADL } & $\mathrm{N}$ & $\%$ \\
\hline Mandiri & 11 & 28,9 \\
Ketergantungan ringan & 22 & 57,9 \\
Ketergantungan sedang & 3 & 7,9 \\
Ketergantungan berat & 2 & 5,3 \\
Ketergantungan total & 0 & 0 \\
\hline
\end{tabular}

Distribusi responden berdasarkan tingkat ketergantungan pada aktivitas sehari-hari dengan menggunakan skor IADL lebih banyak pada kelompok mandiri yaitu sebanyak 16 orang $(42,1 \%)$. Distribusi secara lengkap dapat dilihat pada Tabel 4.

Tabel 4. Distribusi responden berdasarkan skor IADL

\begin{tabular}{lcc}
\hline \multicolumn{1}{c}{ IADL } & N & $\%$ \\
\hline Mandiri & 16 & 42,1 \\
Ketergantungan ringan & 13 & 34,2 \\
Ketergantungan berat & 7 & 18,4 \\
Ketergantungan total & 2 & 5,3 \\
\hline
\end{tabular}

Distribusi responden berdasarkan tipe demensia yang dinilai menggunakan HIS lebih banyak pada $\mathrm{VaD}$ atau demensia vaskular yaitu sebesar 36 orang $(94,7 \%)$ dapat dilihat pada Tabel 5.

Tabel 5. Distribusi responden berdasarkan HIS

\begin{tabular}{lcc}
\hline \multicolumn{1}{c}{ Tipe demensia } & $\mathrm{N}$ & $\%$ \\
\hline $\mathrm{AD}$ & 0 & 0 \\
Demensia Campuran & 2 & 5,3 \\
$\mathrm{VaD}$ & 36 & 94,7 \\
\hline
\end{tabular}

\section{Pembahasan}

\section{Karakteristik responden berdasarkan jenis kelamin}

Hasil penelitian yang disajikan menunjukkan distribusi pasien stroke nonhemoragik dengan diabetes melitus tipe II lebih banyak terjadi pada laki-laki yaitu sebesar $57,9 \%$ dibandingkan pada 
perempuan sebesar $44,1 \%$.

Penelitian ini sejalan dengan penelitian Onwuegbuzi, et al yang menyatakan bahwa stroke nonhemoragik dengan diabetes melitus tipe II lebih banyak ditemukan pada laki-laki dibandingkan perempuan. $^{8}$ Penelitian Iso, et al dalam studi populasi kohort melaporkan bahwa laki-laki dengan diabetes melitus tipe 2 memiliki prevalensi yang lebih besar mengembangkan stroke dibandingkan perempuan. ${ }^{9}$ Hal ini dihubungkan dengan kebiasaan merokok yang sudah menjadi gaya hidup sebagian besar orang terutama laki-laki, dimana merokok ikut berperan terhadap kejadian aterosklerosis pembuluh darah. ${ }^{10}$

\section{Karakteristik responden berdasarkan umur}

Hasil penelitian yang disajikan dalam Tabel 1 menunjukkan distribusi pasien stroke nonhemoragik dengan diabetes melitus tipe 2 lebih banyak terjadi pada rentang umur 55-64 tahun yaitu sebesar 47,4\%, diikuti kelompok umur 45-54 tahun dan kelompok umur 65-74 tahun yang masing-masing sebesar $23,7 \%$ serta distribusi terkecil pada kelompok umur 35-44 tahun dan $\geq 75$ tahun yang masing-masing sebesar $2,6 \%$.

Penelitian ini sejalan dengan penelitian Onwuegbuzi, et al yang menyatakan bahwa distribusi umur terbanyak pada rentang umur 50-69 tahun. ${ }^{8}$ Penelitian Kabi, dkk menyatakan bahwa pasien dengan stroke nonhemoragik lebih banyak terjadi di rentang usia 51-65 tahun. ${ }^{11}$ Stroke nonhemoragik dapat meningkat 2 kali lipat pada seseorang setiap dekadenya setelah berumur 55 tahun. ${ }^{8}$ Hal ini disebabkan oleh gangguan aliran darah yang mana pada orang tua cenderung mengalami degeneratif dan proses aterosklerosis pada pembuluh darah otak. ${ }^{11}$

\section{Karakteristik responden berdasarkan pekerjaan}

Hasil penelitian yang disajikan dalam Tabel 1 menunjukkan distribusi pasien stroke nonhemoragik dengan diabetes melitus tipe 2 lebih banyak bekerja sebagai IRT, yaitu sebesar 34,2\%, diikuti oleh pekerja Swasta sebesar 28,9\%, Pensiunan 23,7\%, dan PNS $13,2 \%$. Penelitian ini menunjukan faktor stroke nonhemoragik lebih cenderung pada responden yang tidak bekerja dibandingkan responden yang memiliki pekerjaan.

Hasil penelitian Kabi, dkk juga menunjukan bahwa pasien stroke nonhemoragik lebih banyak bekerja sebagai IRT. ${ }^{11}$ Penelitian ini sejalan dengan penelitian Patricia, dkk yang dilakukan di RSUP Prof. Dr. R. D. Kandou Manado pada 60 pasien stroke nonhemoragik yang melaporkan bahwa sebesar 30\% responden bekerja sebagai IRT. Hal ini diduga berhubungan dengan stres psikologis akibat pekerjaan yang dapat meningkatkan risiko stroke nonhemoragik yang terjadi pada responden IRT. ${ }^{12}$

\section{Karakteristik responden berdasarkan tingkat pendidikan}

Hasil penelitian yang disajikan dalam Tabel 1 menunjukkan distribusi pasien stroke nonhemoragik dengan diabetes melitus tipe 2 lebih banyak pada responden dengan tingkat pendidikan SMA yaitu sebesar 50\%, diikuti tingkat pendidikan PT/Akademi sebesar $26,3 \%$, SMP sebesar $15,8 \%$ dan yang paling sedikit pada tingkat pendidikan SD yaitu sebesar $7,9 \%$.

Penelitian ini sejalan dengan penelitian Patricia, dkk yang menunjukkan distribusi terbanyak pasien stroke nonhemoragik berdasarkan tingkat pendidikan terakhir adalah SMA. Tingkat pendidikan tidak secara langsung sebagai penyebab stroke namun tingkat pendidikan dapat menggambarkan perilaku hidup sehat seseorang. ${ }^{12}$

\section{Distribusi responden berdasarkan tingkat kognitif}

Hasil penelitian yang disajikan dalam Tabel 2 menunjukkan distribusi pasien stroke nonhemoragik dengan diabetes melitus tipe 2 lebih banyak pada responden dengan gangguan kognitif ringan sebesar $47,4 \%$, diikuti gangguan kognitif sedang sebesar $28,9 \%$, normal $15,8 \%$ dan yang paling sedikit pada gangguan kognitif berat sebesar 7,9\%. Sebagian besar pasien stroke nonhemoragik dengan diabetes melitus tipe 2 mengalami gangguan kognitif yaitu sebesar $84,5 \%$.

Hasil penelitian Totting, dkk tahun 2017 juga menunjukan hal yang serupa, yaitu sebesar $73,3 \%$ pasien stroke nonhemoragik dengan diabetes melitus tipe 2 mengalami gangguan fungsi kognitif. ${ }^{13}$ Stroke disebabkan oleh oklusi lumen pembuluh darah otak sehingga menimbulkan lesi-lesi vaskular di daerah yang dialirinya sehingga menimbulkan manifestasi defisit neurologik seperti hemiparesis dan gangguan fungsi kognitif. ${ }^{12}$

\section{Distribusi responden berdasarkan skor ADL}

Hasil penelitian yang disajikan dalam Tabel 3 menunjukkan distribusi pasien stroke nonhemoragik 
dengan diabetes melitus tipe 2 berdasarkan tingkat ketergantungan pada aktivitas sehari-hari dengan menggunakan skor ADL lebih banyak pada responden dengan ketergantungan ringan yaitu sebesar $60,5 \%$, diikuti dengan responden yang mandiri sebesar $28,9 \%$, ketergantungan sedang dan ketergantungan berat yang masing-masing sebesar $5,3 \%$.

Individu yang telah mengalami stroke tetapi tidak memiliki diabetes melitus memiliki resiko 3,4 kali untuk memiliki keterbatasan dalam ADL. Resiko ini lebih meningkat 2 kali lipatnya bagi individu yang memiliki stroke disertai diabetes melitus. ${ }^{14}$ Hal tersebut juga didukung oleh penelitian Kusumaningsih, et al yang menyatakan bahwa secara klinis faktor resiko diabetes melitus berhubungan kuat dengan munculnya ketergantungan ADL pada pasien stroke kronik. ${ }^{15}$

\section{Distribusi responden berdasarkan skor IADL}

Hasil penelitian yang disajikan dalam Tabel 6 menunjukkan distribusi pasien stroke nonhemoragik dengan diabetes melitus tipe 2 berdasarkan tingkat ketergantungan pada aktivitas sehari-hari dengan menggunakan skor IADL lebih banyak pada responden tingkat mandiri sebesar $42,1 \%$, diikuti dengan responden ketergantungan ringan sebesar $34,2 \%$, ketergantungan berat sebesar $18,4 \%$ dan ketergantungan total sebesar 5,3\%.

Pasien stroke nonhemoragik memiliki peluang meningkatkan ketergantungan IADL sebesar 50\% dibandingkan populasi normal. ${ }^{16}$

\section{Distribusi responden berdasarkan HIS}

Hasil penelitian yang disajikan dalam Tabel 8 menunjukkan distribusi pasien stroke nonhemoragik dengan diabetes melitus tipe 2 berdasarkan tipe demensia yang dinilai menggunakan HIS lebih banyak mengalami $\mathrm{VaD}$ sebesar $94,7 \%$, diikuti demensia campuran $5,3 \%$ dan tidak terdapat responden dengan $\mathrm{AD}$.

Pasien stroke dengan diabetes melitus meningkatkan resiko demensia sebesar 1,25 kali dibandingkan dengan pasien stroke tanpa diabetes melitus. ${ }^{17}$ Diabetes melitus tipe 2 dikaitkan dengan penyakit pembuluh darah yang akhirnya mengarah kepada disfungsi kognitif dan VaD. Penelitian terbaru telah menunjukkan bahwa diabetes melitus tipe 2 juga beresiko pada AD melalui resisten insulin. Namun saat ini belum dipahami secara jelas tautan molekul antara stroke dan AD. ${ }^{18}$

\section{Kesimpulan}

Berdasarkan hasil penelitian dari total 38 pasien stroke nonhemoragik dengan diabetes melitus tipe 2 di Poli Saraf RSUD Sultan Syarif Mohamad Alkadrie Pontianak dijumpai gambaran demensia vaskuler pada $36(94,7 \%)$ pasien stroke nonhemoragik dengan diabetes melitus tipe 2 .

\section{Saran}

Perlu diadakan penelitian lebih luas dengan menggunakan NINDS-AIREN (The National Institute of Neurological Disorders and Stroke Association Internationale pour la Recherche et l'Enseignement en Neurosciences) untuk mengklasifikasikan pasien berdasarkan kriteria diagnosis klinis probable, possible, dan difinite $\mathrm{VaD}$ karena data menggunakan bukti pemeriksaan pencitraan otak atau bukti histopatologi sehingga data yang didapat lebih akurat. Sebelum dilakukan penelitian, pastikan bahwa kelengkapan data di Rumah Sakit telah lengkap termasuk gambaran pencitraan otak pasien. Kepada pasien diharapkan meningkatkan kesadaran dan kewaspadaan terhadap kesehatan dengan rutin melakukan konsultasi dan pemeriksaan gula darah, menerapkan pola makan yang sehat serta meningkatkan aktivitas fisik.

\section{Daftar Pustaka}

1. World Health Organization. Dementia [Internet]. 2017 [cited 2018 Dec 12]. Available from: http://www.who.int/news-room/fact-sheets/detail/dem entia.

2. Riyanto R, Brahmadhi A. Pengaruh subtype stroke terhadap terjadinya demensia vascular pada pasien post stroke di RSUD Prof. Dr. Margono Soekarjo. Medisains. 2017;15(1):23-30.

3. O'Brien JT, Thomas A. Vascular dementia. Lancet. 2015;386(10004):1698-706.

4. Johnson W, Onuma O, Owolabi M, Sachdev S. Stroke: A global response is needed. Bulletin of the World Health Organization. 2016;634-634A.

5. Hu X, Michael De Silva T, Chen J, Faraci FM. Cerebral vascular disease and neurovascular injury in ischemic stroke. Circ Res. 2017;120(3):449-71.

6. Chen R, Ovbiagele B, Feng W. Diabetes and stroke: epidemiology, pathophysiology, pharmaceuticals and outcomes. Am J Med Sci. 2016;351(4):380-6.

7. International Diabetes Federation. IDF diabetes atlas. 8th ed. International Diabetes Federation; 2017. p. $18,44,46$.

8. Onwuegbuzie GA, Reng RS. Diabetes as a risk factor for ischemic stroke in a tertiary health care center, Abuja. N Niger J Clin Res. 2018;7(11):16-20.

9. Iso H, Imano H, Kitamura A, Sato S, Naito Y, Ohira $\mathrm{T}$, et al. Type 2 diabetes and risk of non-embolic 
ischaemic stroke in japanese men and women. Diabetologia. 2004;47(12):2137-44.

10. Tumeleng P, Runtuwene T, Kembuan M. Sebaran Kebiasaan merokok pada pasien stroke iskemik yang di rawat inap di bagian neurologi RSU Prof. Dr. R. D. Kandou Manado. e-CliniC. 2015;3(1):262-6.

11. Kabi GYCR, Tumewah R, Kembuan MAHN Gambaran faktor risiko pada penderita stroke iskemik yang dirawat inap neurologi RSUP Prof. Dr. R. D Kandou Manado periode Juli 2012 - Juni 2013. e-CliniC. 2015;3(1):1-6.

12. Patricia H, Kembuan MAHN, Tumboimbela MJ. Karakteristik penderita stroke iskemik yang di rawat inap di RSUP Prof. Dr. R. D. Kandou Manado tahun 2012-2013. e-Clinic. 2015;3(1):445-51.

13. Totting S, Pinzon RT, Widiasmoko B. Hubungan diabetes mellitus dengan gangguan fungsi kognitif post stroke iskemik di Rumah Sakit Bethesda. J Kesehat Andalas. 2017;6(3):647-53.

14. Andrade FCD, Guevara PE, Lebrão ML, De Oliveira Duarte YA. Correlates of the incidence of disability and mortality among older adult brazilians with and without diabetes mellitus and stroke. BMC Public Health. 2012;12:361.

15. Kusumaningsih W, Rachmayanti S, Werdhani RA. Relationship between risk factors and activities of daily living using Modified Shah Barthel Index in stroke patients. J Phys Conf Ser. 2017;884(1):1-16.

16. Synhaeve NE, Arntz RM, van Alebeek ME, van Pamelen J, Maaijwee NAM, Rutten-Jacobs LCA, et al. Women have a poorer very long-term functional outcome after stroke among adults aged 18-50 years: the future study. J Neurol. 2016;263(6):1099-105.

17. Surawan J, Areemit S, Tiamkao S, Sirithanawuthichai T, Saensak S. Risk factors associated with post-stroke dementia: a systematic review and meta-analysis. Neurol Int. 2017;9(3):63-8.

18. Vijayan M, Reddy PH. Stroke, Vascular dementia, and Alzheimer's Disease: Molecular Links. J Alzheimer's Dis. 2016;54(2):427-43. 